\title{
Role of steroids in the treatment of bacterial keratitis
}

This article was published in the following Dove Press journal:

Clinical Ophthalmology

27 January 2016

Number of times this article has been viewed
Sotiria Palioura

Christopher R Henry

Guillermo Amescua

Eduardo C Alfonso

Department of Ophthalmology, Bascom Palmer Eye Institute, University of Miami Miller School of Medicine, Miami, FL, USA
Correspondence: Christopher R Henry Department of Ophthalmology, Bascom Palmer Eye Institute, University of Miami Miller School of Medicine, 900 NW 17th Street, Miami, FL 33136, USA Tel +I 3053266000

Email chenry2@med.miami.edu
Abstract: Bacterial keratitis can lead to severe visual impairment from corneal ulceration, subsequent scarring, and possible perforation. The mainstay of treatment is topical antibiotics, whereas the use of adjunctive topical corticosteroid drops remains a matter of debate. Herein, we review the rationale for and against the use of topical corticosteroids and we assess their effectiveness and safety in the published randomized controlled trials that have evaluated their role as adjunctive therapy for bacterial corneal ulcers. In the largest study to date, the Steroids for Corneal Ulcers Trial, topical corticosteroid drops were neither helpful nor harmful for the 500 participants as a whole. However, subgroup analyses suggested that topical corticosteroids may be beneficial upon early administration (within 2-3 days after starting antibiotics) for more central corneal ulcers with poorer vision at presentation, for invasive Pseudomonas strains, and for non-Nocardia ulcers. These results are discussed within the limitations of the study.

Keywords: topical corticosteroids, corneal ulcer, eye infection, antibiotic, endophthalmitis, perforation

\section{Introduction}

Keratitis is an inflammation of the cornea which, when severe, can be sight threatening. Because keratitis can result from both infectious and noninfectious etiologies, diagnosis and management can sometimes prove challenging. Out of the estimated 30,000 cases of microbial (bacterial, fungal, and parasitic) keratitis that occurs annually in the USA, the vast majority are bacterial in nature. ${ }^{1,2}$ The incidence of bacterial keratitis is ten times higher in tropical climates and developing nations than in temperate environments and in the developed world. ${ }^{2-9}$ Risk factors for bacterial keratitis include contact lens wear, corneal trauma, ocular surface disease, history of ocular or eyelid surgery, HIV infection, and immunodeficiency. ${ }^{4,5}$ Organisms that comprise the normal ocular flora, such as Streptococci and Staphylococci, can lead to ulceration if normal host defenses are violated. ${ }^{10-12}$ In contact lens wearers, a higher prevalence of bacterial keratitis due to gram-negative rods (eg, Pseudomonas spp.) is seen. ${ }^{13,14}$

Patients with bacterial keratitis typically present with decreased vision, pain, and photophobia. Clinical signs include a corneal epithelial defect that stains with fluorescein and associated stromal infiltrate. In severe cases, the loss of stromal tissue and ulceration occur (Figure 1). The extent of visual loss depends on the size and location of the infiltrate as well as on the surrounding corneal edema. The severity of the corneal infection generally correlates with the degree of anterior chamber cellular reaction and possible hypopyon formation. Intraocular pressure can be high due to obstruction of the trabecular meshwork by inflammatory cells or low due to ciliary body inflammation and aqueous hyposecretion. ${ }^{15}$ 

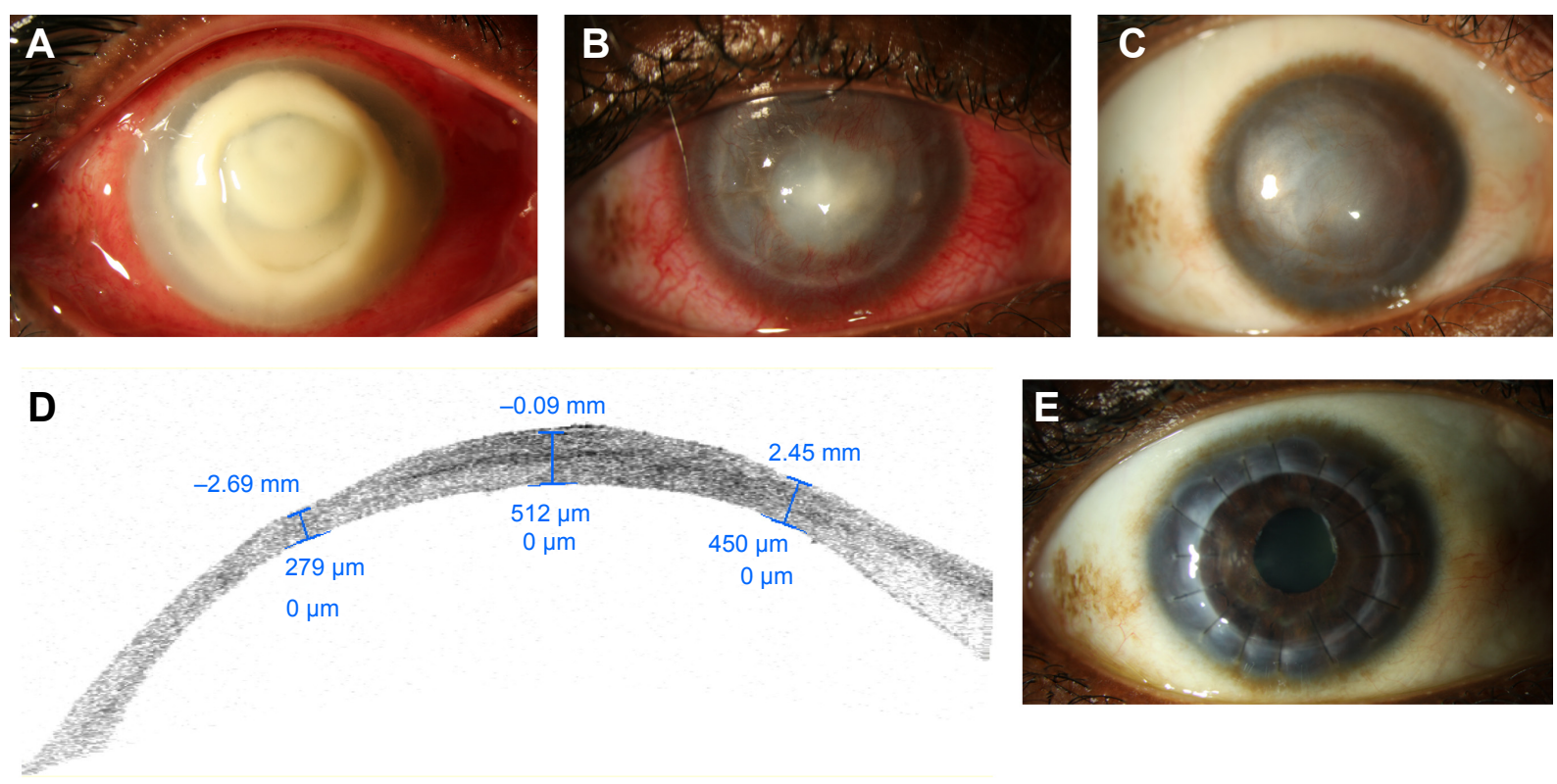

Figure I Slit lamp photograph of the right eye of 35-year-old contact lens wearer with Pseudomonas keratitis.

Notes: (A) At presentation, a suppurative infiltrate encompassing most of the cornea as well as a $3.5 \mathrm{~mm}$ hypopyon is seen. (B) One month after treatment with fortified topical antibiotics, cornea collagen cross-linking, amniotic membrane transplantation, and topical corticosteroids, the infiltrate is much smaller and peripheral corneal neovascularization and scarring are observed. (C) Six months later, diffuse scarring limits the patient's vision. (D) Anterior segment OCT at I year shows significant peripheral and central thinning. (E) One year after penetrating keratoplasty, the patient's vision is 20/60.

Abbreviation: OCT, optical coherence tomography.

Corneal scrapings for smears and cultures are the gold standard for the diagnosis of bacterial keratitis, and the corneal examination alone is not enough to discriminate between bacterial and other forms of infectious or noninfectious keratitis, even for experienced clinicians. ${ }^{16}$ Empirical therapy with topical antibiotics is generally started at presentation and tailored according to microbiologic results, taking into consideration the size and severity of the infection. ${ }^{15}$ Inadequate control of the infection can lead to severe ulceration, perforation, endophthalmitis, blindness, and even loss of the eye. ${ }^{17}$ Unfortunately, even if the causative organisms are eradicated, the loss of vision can ensue from the subsequent scarring and vascularization of the cornea. Anterior lamellar keratoplasty or full thickness corneal transplantation may then be necessary to restore visual clarity. The long-term prognosis for corneal grafts after history of severe corneal ulcers is guarded..$^{15,17}$

\section{Topical corticosteroids: a controversial issue}

Although the use of topical antibiotics is mandatory for the treatment of bacterial keratitis, the addition of topical corticosteroid drops remains a matter of debate. ${ }^{18,19}$ Proponents for the early institution of topical corticosteroids in bacterial keratitis argue that corticosteroids can reduce the severity of corneal stromal melt, neovascularization, and subsequent scarring which occur as a result of the host inflammatory and immune responses to the bacterial infection. ${ }^{20-22}$ Corticosteroids are also believed to improve patient compliance with frequent instillation of fortified antibiotics by decreasing pain and discomfort. In the acute phase of the infection, bacterial toxins interact with injured epithelial and stromal cells and activated immune cells release an array of cytokines, collagenases, and growth factors that lead to keratocyte apoptosis and destruction of collagen. ${ }^{23,24}$ As the infection clears, viable keratocytes are transformed to activated fibroblasts that function to restore tissue loss. ${ }^{23,25}$ Because fibroblasts deposit newly made collagen and extracellular matrix in an irregular fashion, corneal haze and scarring often ensue. ${ }^{26}$ Topical corticosteroid drops are known to inhibit neutrophil chemotaxis and are, thus, believed to reduce the collagenase and cytokine burden that leads first to ulceration and then to scarring. ${ }^{20-22}$ Advocates against the use of topical corticosteroids in bacterial keratitis argue that epithelial healing is delayed ${ }^{27,28}$ and neutrophil inhibition may exacerbate the infection, particularly if the treatment with antibiotics is inadequate..$^{29,30}$

Four randomized controlled trials have been conducted to date aiming to assess the effect of corticosteroids on bacterial keratitis (Table 1). ${ }^{31-36}$ All four studies compared an antibiotic group with an antibiotic-corticosteroid group, though different formulations of antibiotics and corticosteroids were chosen by each group of investigators. Outcomes included vision, ulcer healing rate, time to re-epithelialization, and 
Table I Summary of randomized controlled trials on the adjunctive use of topical corticosteroids for bacterial keratitis

\begin{tabular}{|c|c|c|c|}
\hline $\begin{array}{l}\text { Author } \\
\text { (year, location) }\end{array}$ & $\begin{array}{l}\text { Type of intervention } \\
\text { (no of eyes) }\end{array}$ & $\begin{array}{l}\text { Outcome measures } \\
\text { (follow-up interval) }\end{array}$ & $\begin{array}{l}\text { P-value } \\
\text { (steroid vs placebo) }\end{array}$ \\
\hline $\begin{array}{l}\text { Carmichael et al }{ }^{31} \\
(1990, \text { South Africa) }\end{array}$ & $\begin{array}{l}\text { Cefazolin } 32 \mathrm{~g} / \mathrm{L} \text { and gentamicin } \mathrm{I} 4 \mathrm{~g} / \mathrm{L}(40) \\
\text { plus } \\
\text { dexamethasone } 0.1 \%(2 \mathrm{I}) \text { vs placebo (19) }\end{array}$ & $\begin{array}{l}\text { Ulcer healing rate } \\
\text { BCVA } \\
\text { Adverse events } \\
\text { ( } 2 \text { months) }\end{array}$ & $\begin{array}{l}>0.05 \\
>0.05 \\
>0.05\end{array}$ \\
\hline $\begin{array}{l}\text { Srinivasan et a }{ }^{32} \\
(2009, \text { India })\end{array}$ & $\begin{array}{l}\text { Moxifloxacin } 0.5 \%(42) \\
\text { plus } \\
\text { prednisolone phosphate I\% (20) vs placebo (22) }\end{array}$ & $\begin{array}{l}\text { BCVA } \\
\text { Time to re-epithelialization } \\
\text { Infiltrate/scar size } \\
\text { Adverse events } \\
\text { ( } 3 \text { weeks and } 3 \text { months) }\end{array}$ & $\begin{array}{l}>0.05 \\
0.03 \\
>0.05 \\
>0.05\end{array}$ \\
\hline $\begin{array}{l}\text { Blair et al }{ }^{33} \\
\text { (20II, Canada) }\end{array}$ & $\begin{array}{l}\text { Gatifloxacin } 0.5 \%(30) \\
\text { plus } \\
\text { dexamethasone } 0.1 \% \text { (15) vs placebo (15) }\end{array}$ & $\begin{array}{l}\text { Ulcer size (photograph) } \\
\text { Ulcer size (clinician estimate) } \\
\text { BCVA } \\
\text { Quality of life } \\
\text { Time to healing } \\
\text { Adverse events } \\
\text { ( } 2.5 \text { months) }\end{array}$ & $\begin{array}{l}>0.05 \\
0.05 \\
>0.05 \\
>0.05 \\
>0.05 \\
>0.05\end{array}$ \\
\hline $\begin{array}{l}\text { Srinivasan et a }{ }^{34,35} \\
(20 I 2, \text { India and USA })^{a}\end{array}$ & $\begin{array}{l}\text { Moxifloxacin } 0.5 \%(500) \\
\text { plus } \\
\text { prednisolone phosphate I\% (250) vs placebo }(250)\end{array}$ & $\begin{array}{l}\text { BCVA } \\
\text { Infiltrate/scar size } \\
\text { Time to re-epithelialization } \\
\text { Adverse events } \\
\text { ( } 3 \text { weeks and } 3 \text { months) }\end{array}$ & $\begin{array}{l}>0.05 \\
>0.05 \\
>0.05 \\
>0.05\end{array}$ \\
\hline
\end{tabular}

Notes: additional subgroup analyses, 12 -month and 4 -year follow-up results are discussed in the text. Placebo was $0.9 \%$ sodium chloride.

Abbreviation: BCVA, best-corrected visual acuity.

adverse events, yet each study reported them at different time points (Table 1). The first three trials did not show any harm or benefit from the adjunctive use of topical corticosteroid drops in bacterial keratitis, but results were limited by the small number of participants. ${ }^{31-33}$

The study by Carmichael et al was conducted in South Africa and randomized 40 eyes of 39 participants. ${ }^{31}$ All patients received fortified cefazolin $32 \mathrm{~g} / \mathrm{L}$ and gentamicin $14 \mathrm{~g} / \mathrm{L}$ hourly for 24 hours before the initiation of dexamethasone $0.1 \%$ four times a day or placebo. Dexamethasone $0.1 \%$ was continued until complete healing with a minimum of 2 weeks. The corticosteroid tapering regimen is not provided by the authors. The most common organisms isolated in both groups were of the Streptococcus spp. and Staphylococcus spp. Interestingly, in both groups, approximately one-third of the patients had "no growth" on culture plates. The study by Blair et al was carried out in Canada and included 30 randomized participants. ${ }^{33}$ All patients received gatifloxacin $0.5 \%$ hourly for 48 hours prior randomization to either dexamethasone $0.1 \%$ four times a day or placebo. Dexamethasone $0.1 \%$ was given four times a day for 3 weeks, it was then tapered to two times a day for a week and then to once a day for the fifth week. Patients received gatifloxacin $0.5 \%$ four times a day for a total of 4 weeks, that is, in the fifth week they were only on a daily corticosteroid drop. Out of the bacterial isolates cultured, $60 \%(\mathrm{n}=18)$ were Staphylococcus spp. and $17 \%(\mathrm{n}=5)$ were Pseudomonas aeruginosa isolates.

Both studies ${ }^{31,33}$ reported no statistically significant difference in terms of best-corrected vision, ulcer healing rate, and adverse events at a mean follow-up of $2^{31}$ or 2.5 months between the two groups of patients. ${ }^{33}$ Blair et al reported that mean residual ulcer size at 10 weeks, as estimated by the clinician, was smaller for the antibiotic-corticosteroid group than the antibiotic-placebo group ( $P$-value, 0.05$)$. However, this difference was not statistically significant when residual ulcer size was estimated from anterior segment photographs at presentation and at the 10-week follow-up interval ( $P$-value, 0.56$)$.

An initial study by Srinivasan et al served as a pilot analysis for the largest randomized controlled trial on this issue, the Steroids for Corneal Ulcers Trial (SCUT). ${ }^{32}$ The pilot study included 42 randomized participants with culture-proven bacterial keratitis and was conducted in South India. All participants were pretreated with moxifloxacin $0.5 \%$ hourly (while awake) for 48 hours before the initiation of either topical corticosteroid (prednisolone sodium phosphate $1 \%$ ) or placebo four times a day. Patients were given topical corticosteroids four times a day for 1 week, two times a day for 1 week, and once a day for the third week. Topical antibiotic was 
given every 2 hours while awake until re-epithelialization, and it was then reduced to four times a day until the end of the third week. Approximately $50 \%$ of all bacterial isolates were Streptococcus spp. and 20\% were Pseudomonas spp. At a mean follow-up of 3 months, there was no difference in corneal scar size, best-corrected visual acuity (BCVA), and adverse effects between the two patient groups. However, a statistically significant delay in re-epithelialization was noted in the corticosteroid-treated group. ${ }^{32}$

The results of this pilot study paved the way for the landmark SCUT trial, which was started in 2006, enrolled 500 participants by 2010 , and published the first results in $2012 . .^{34,35}$ Several sub-studies and subgroup analyses of the SCUT have been published over the past 3 years and comprise the best evidence we have to address the controversy over the use of corticosteroids in bacterial keratitis. ${ }^{37-46}$ The SCUT study was a prospective, randomized 1:1, placebo-controlled, double-masked, multicenter clinical trial that compared the administration of prednisolone sodium phosphate $1 \%$ with placebo as adjunctive therapy for the treatment of cultureconfirmed bacterial corneal ulcers. All participants were pretreated with hourly administration (while awake) of moxifloxacin $0.5 \%$ for 48 hours before the addition of topical corticosteroid or placebo..$^{34,35}$ The antibiotic was then reduced to every 2 hours until the resolution of the epithelial defect and then four times a day until 3 weeks from enrollment. Patients were enrolled in the trial 2-6 days after presentation, that is, upon confirmation of a positive bacterial culture. The study drug (prednisolone phosphate $1 \%$ or placebo) was administered four times a day for 1 week after randomization, and it was then tapered to two times a day for a week, and then once a day for a week. Of the cultured bacterial isolates, $72 \%$ were gram-positive species and $28 \%$ gram-negative ones. Streptococcus pneumoniae accounted for $\sim 50 \%$ of all isolates, Staphylococcus spp. for $\sim 35 \%$ of the isolates, Nocardia spp. for $11 \%$ of the isolates, and P. aeruginosa for $22 \%$ of the isolates. The main outcome measure was the improvement in BCVA at 3 months from enrollment. Secondary outcomes included rates of corneal perforation, size of the scar, rate of epithelial healing, and BCVA at 3 weeks, 3 months, and 12 months. Moreover, investigators assessed whether clinical outcomes correlated with the minimum inhibitory concentration (MIC) to moxifloxacin for the causal bacterial organism.

Out of the 500 participants, follow-up data were available on 442 patients at 3 months $(88.4 \%)$ and 399 patients at 12 months (79.8\%). In terms of baseline characteristics, the only difference between the corticosteroid group
(222 participants at 3 months) and the placebo group (220 participants at 3 months) was the presence of more central ulcers in the corticosteroid group ( $P$-value, 0.02$)$. In terms of outcomes, there was no statistically significant difference between the two groups as far as BCVA, size of scar, time to resolution of the epithelial defect, or rate of perforation are concerned. Counterintuitively, more participants in the placebo arm experienced a statistically significant increase in intraocular pressure $(25-35 \mathrm{mmHg})$ than in the topical corticosteroid arm ( $P$-value, 0.04$)$.

Overall, subsequent subgroup analysis showed more favorable results for the topical corticosteroid group for certain subsets of participants at 3- month follow up. First, central ulcers covering the pupil (at least $4 \mathrm{~mm}$ in size) showed a two-line improvement in the corticosteroid group compared with those of the placebo group ( $P$-value, 0.02$)$. Second, patients with worse vision at presentation (counting fingers or worse) improved by 1.5 lines more in the corticosteroid group than in the placebo group ( $P$-value, 0.03$)$. Finally, there was a statistical trend for deeper and larger ulcers to show a 1.5-line visual improvement in the corticosteroid group than in the placebo group ( $P$-value, 0.07$)$.

A common cause of fulminant bacterial keratitis is infection with Pseudomonas spp. Indeed, 110 of the 500 participants in the SCUT study were diagnosed with Pseudomonas keratitis. Subgroup analysis showed that patients with corneal ulcers due to $P$. aeruginosa had worse vision at presentation than patients with other bacterial ulcers ( $P$-value, 0.001$).{ }^{46}$ Ninety-nine of the 110 enrolled patients $(90 \%)$ returned for the 3-month follow-up visit, and at that time, their vision was significantly better than patients with non-Pseudomonas ulcers ( $P$-value, 0.004$)$. The use of adjunctive corticosteroids did not statistically improve BCVA and size of scar at 3 months compared with the use of placebo. The rate of adverse events such as perforations, recurrence of epithelial defect, and rise in intraocular pressure was similar between Pseudomonas and non-Pseudomonas ulcers and between the corticosteroid and the placebo arm. ${ }^{46}$ Interestingly, different Pseudomonas strains showed differential response to adjunctive corticosteroids. ${ }^{47}$ Corneal ulcers due to invasive Pseudomonas strains had better vision by 2.5 lines at 3 months if topical corticosteroids had been used $(P$-value, 0.04$)$. In contrast, corneal ulcers due to cytotoxic Pseudomonas strains did better in the placebo arm than in the corticosteroid arm in terms of 3-month BCVA, though the difference was not statistically significant ( $P$-value, 0.07$)$.

A significant percentage of patients $(11 \%)$ in the SCUT trial had corneal ulcers due to Nocardia spp. ${ }^{34,38}$ Most of 
these patients were agricultural workers and almost $60 \%$ of them had a history of antecedent trauma. They had better presenting visual acuity compared with non-Nocardia patients (20/45 vs 20/145, respectively, $P$-value, 0.001$)$ and were symptomatic for a longer time before presentation (10 vs 4 days). Sensitivity of the isolated Nocardia spp. to fluoroquinolones ranged from $45 \%$ to $100 \% .{ }^{38}$ Regardless of the treatment arm (corticosteroid vs placebo), patients with Nocardia ulcers experienced less improvement in vision than patients with other bacterial ulcers. Moreover, patients with Nocardia keratitis who received corticosteroids had a larger infiltrate or scar size in both 3 and 12 months when compared with placebo ( $P$-value, 0.03$)$. Upon exclusion of the Nocardia cases from the overall group, the corticosteroid-treated arm had better vision by one line at 12 months compared with the placebo arm $(P$-value, 0.02$){ }^{34}$

Patients enrolled in the SCUT study received topical antibiotics for at least 2 days and sometimes up to 34 days before the initiation of topical corticosteroid or placebo due to "trial enrollment procedures" as per the study administrators. ${ }^{42}$ Early (ie, within 2-3 days) administration of corticosteroids was associated with a one-line improvement in BCVA at 3 months ( $P$-value, 0.01$)$ compared with placebo. In contrast, patients who had 4 or more days of topical antibiotics before the initiation of corticosteroids had one-line worse visual acuity at 3 months compared with the placebo group, which was attributed to the presence of a large number of Nocardia ulcers in this group. Thus, when patients with Nocardia keratitis were excluded from the analysis, corticosteroids were found to be beneficial when administered early leading to 1.3 lines of improvement at 3 months compared with placebo and neutral when given later. Early initiation of corticosteroids resulted in the improvement in visual acuity by at least one-line across ulcers of all severities compared with placebo. ${ }^{42}$ It is clear from the SCUT study that corticosteroids should be avoided in Nocardia ulcers, and it seems that early administration of corticosteroids may be beneficial, while late administration is no different than placebo.

For a subset of 50 patients from the original SCUT study, visual outcomes at 4 years have been reported. ${ }^{39}$ Twentyfour of these patients were in the corticosteroid group and 26 in the placebo arm. Visual acuity improved most during the first 3 weeks of treatment (by 2.9 lines) and then continued to improve slowly over the first year. Between 12 months and 4 years, there was no statistically significant improvement in vision (0.04-line improvement; $P$-value, 0.88 ), which suggests that no significant scar remodeling occurs after the first year. Finally, there was no statistically significant difference in BCVA at 4 years for the 24 patients in the corticosteroid group compared with the 26 patients in the placebo group ( $P$-value, 0.53).

All four randomized controlled trials agreed that corticosteroids did not increase the risk of adverse events, including perforation and endophthalmitis. When we looked at the risk of developing endophthalmitis from infectious keratitis over a 15-year period at the Bascom Palmer Eye Institute, we found a low overall risk of $0.5 \%$ (49 cases out of 9,934 positive corneal cultures). ${ }^{17}$ Of those 49 patients, 23 had bacterial keratitis and 26 fungal keratitis, and $76 \%$ of them were previously on topical corticosteroids. The development of endophthalmitis was a devastating complication, with $70 \%$ of these patients having very poor vision $(<5 / 200)$ at the last follow-up visit, and 15 of the 49 patients requiring enucleation or evisceration.

The management of bacterial keratitis is more challenging in the setting of a corneal allograft since it can lead to graft rejection or failure. The incidence of microbial keratitis following keratoplasty ranges between $1.76 \%$ and $7.4 \%$ in the developed world ${ }^{48-54}$ and up to $12.1 \%$ in developing nations. ${ }^{55,56}$ Most post-keratoplasty infections occur within the first year, and graft clarity is maintained only in $23 \%-50 \%$ of the cases. ${ }^{49,51,57-59}$ There are no randomized controlled trials on the use of corticosteroids for bacterial keratitis in the setting of a corneal allograft. The consensus from the reported studies and our empirical experience suggest that corticosteroids should be cut in half until the culture-positive bacterial infection is well controlled and the epithelial defect is almost healed. For patients with a distant history of a corneal allograft and who are not on corticosteroids at baseline anymore, intensive topical antibiotics should be used for at least 48 hours before the initiation of topical corticosteroids and with the support or microbiological results that demonstrate a bacterial etiology. ${ }^{48-54,57-59}$

\section{Conclusion}

In making a therapeutic decision, well-designed randomized controlled trials can aid us in weighing risks and benefits of the use of topical corticosteroid drops in the setting of bacterial keratitis. In all four studies to date, there was no overall improvement in vision in the corticosteroid-treated group compared with that of the placebo group. Importantly, there was also no difference in adverse effects between the two groups in terms of the rates of perforation, poor control of intraocular pressure, or delay in re-epithelialization. Subgroup analyses of the SCUT study participants showed 
that patients with vision equal to count fingers or worse or with more central ulcers experienced a two-line vision improvement at 3 months when treated with adjunctive corticosteroids. Moreover, non-Nocardia ulcers showed one-line improvement at 12 months when treated with corticosteroids, while the early administration of corticosteroids was linked to better vision at 3 months for ulcers of all severities. Although strain typing is not a standard practice at this time, the SCUT study showed that bacterial keratitis due to invasive Pseudomonas strains benefits from topical corticosteroids.

The results of the SCUT study should be evaluated within the study's limitations. First, the vast majority of patients (97\%) were enrolled in India, there were only eight contact lens wearers in the entire group, and $>300$ patients had a history of trauma. Thus, the study population may not be representative of the patients typically seen in the Western world. This also explains the high prevalence of Nocardia (11\%) and S. pneumoniae (50\%) infections within this group. Moreover, the antibiotic of choice was moxifloxacin $0.5 \%$ for all bacterial ulcers, though different MICs were noted for different causal organisms and the higher MICs were correlated with worse BCVA at the 3-week follow-up visit. ${ }^{37,40,41}$ Finally, all patients received a standard corticosteroid taper over the course of 3 weeks with the most frequent dosing being four times a day during the first week. It is possible that a different dosing regimen with more intensive corticosteroid administration could have different results.

Careless use of corticosteroids in corneal ulcers of unknown origin has significant risks. If the causal organism ends up being fungus, Acanthamoeba, or Nocardia, early use of corticosteroids can be detrimental and could result in the loss of vision or even the eye itself. Thus, topical corticosteroids are to be avoided in most atypical or indolent cases of keratitis. It is important to note that all participants in the SCUT study had good microbiological testing and confirmed culture-positive bacterial keratitis. For non-Nocardia central culture-positive corneal ulcers with no atypical features, the SCUT study showed that the administration of topical corticosteroids may be of benefit, especially if corticosteroids are started within 2-3 days of intensive topical antibiotics. In our institution, we do use corticosteroids for gram-negative and Streptococcal corneal ulcers with a clear microbiological diagnosis and at least after 48 hours of topical antibiotics. ${ }^{15}$ Yet, even for culturepositive bacterial keratitis, one should always keep in mind that a secondary fungal superinfection may ensue upon starting corticosteroids in patients with history of trauma, poor contact lens hygiene, and in tropical regions. Thus, it is crucial to monitor such patients frequently and to have a low threshold for stopping topical corticosteroids if the infection worsens after initial improvement. Future studies that further classify microorganisms based on molecular diagnosis will determine virulence factors such as toxin production. This may help guide treatment that specifically inhibits this initial event in the inflammatory cascade.

\section{Acknowledgment}

Sotiria Palioura holds the 2015 "Spyros Georgaras" scholarship from the Hellenic Society of Intraocular Implant and Refractive Surgery. Christopher R Henry is a recipient of a Heed Ophthalmic Foundation Fellowship.

\section{Disclosure}

The authors report no conflicts of interest in this work.

\section{References}

1. Pepose JS, Wilhelmus KR. Divergent approaches to the management of corneal ulcers. Am J Ophthalmol. 1992;114(5):630-632.

2. Jeng BH, Gritz DC, Kumar AB, et al. Epidemiology of ulcerative keratitis in Northern California. Arch Ophthalmol. 2010;128(8): 1022-1028.

3. Erie JC, Nevitt MP, Hodge DO, et al. Incidence of ulcerative keratitis in a defined population from 1950 through 1988. Arch Ophthalmol. 1993; 111(12):1665-1671.

4. Ibrahim YW, Boase DL, Cree IA. Epidemiological characteristics, predisposing factors and microbiological profiles of infectious corneal ulcers: the Portsmouth corneal ulcer study. Br J Ophthalmol. 2009; 93(10):1319-1324.

5. Upadhyay MP, Karmacharya PC, Koirala S, et al. The Bhaktapur eye study: ocular trauma and antibiotic prophylaxis for the prevention of corneal ulceration in Nepal. Br J Ophthalmol. 2001;85(4): 388-392.

6. Gonzales CA, Srinivasan M, Whitcher JP, et al. Incidence of corneal ulceration in Madurai district, South India. Ophthalmic Epidemiol. 1996; 3(3):159-166.

7. Burton MJ, Pithuwa J, Okello E, et al. Microbial keratitis in East Africa: why are the outcomes so poor? Ophthalmic Epidemiol. 2011; 18(4):158-163.

8. Kaliamurthy J, Kalavathy CM, Parmar P, et al. Spectrum of bacterial keratitis at a tertiary eye care centre in India. Biomed Res Int. 2013; 2013:181564.

9. Schaefer F, Bruttin O, Zografos L, et al. Bacterial keratitis: a prospective clinical and microbiological study. Br J Ophthalmol. 2001;85(7): 842-847.

10. Mino de Kaspar H, Koss MJ, He L, et al. Antibiotic susceptibility of preoperative normal conjunctival bacteria. Am J Ophthalmol. 2005; 139(4):730-733.

11. Hsu HY, Lind JT, Tseng L, et al. Ocular flora and their antibiotic resistance patterns in the midwest: a prospective study of patients undergoing cataract surgery. Am J Ophthalmol. 2013;155(1):36-44.e2.

12. Park SH, Lim JA, Choi JS, et al. The resistance patterns of normal ocular bacterial flora to 4 fluoroquinolone antibiotics. Cornea. 2009; 28(1):68-72.

13. Dart JK, Stapleton F, Minassian D. Contact lenses and other risk factors in microbial keratitis. Lancet. 1991;338(8768):650-653.

14. Schein OD, Ormerod LD, Barraquer E, et al. Microbiology of contact lens-related keratitis. Cornea. 1989;8(4):281-285. 
15. Amescua G, Miller D, Alfonso EC. What is causing the corneal ulcer? Management strategies for unresponsive corneal ulceration. Eye (Lond). 2012;26(2):228-236.

16. Dahlgren MA, Lingappan A, Wilhelmus KR. The clinical diagnosis of microbial keratitis. Am J Ophthalmol. 2007;143(6):940-944.

17. Henry CR, Flynn HW Jr, Miller D, et al. Infectious keratitis progressing to endophthalmitis: a 15-year study of microbiology, associated factors, and clinical outcomes. Ophthalmology. 2012;119(12): 2443-2449.

18. Hindman HB, Patel SB, Jun AS. Rationale for adjunctive topical corticosteroids in bacterial keratitis. Arch Ophthalmol. 2009;127(1): 97-102.

19. Cohen EJ. The case against the use of steroids in the treatment of bacterial keratitis. Arch Ophthalmol. 2009;127(1):103-104.

20. Den S, Sotozono C, Kinoshita S, et al. Efficacy of early systemic betamethasone or cyclosporin A after corneal alkali injury via inflammatory cytokine reduction. Acta Ophthalmol Scand. 2004;82(2):195-199.

21. Yi K, Chung TY, Hyon JY, et al. Combined treatment with antioxidants and immunosuppressants on cytokine release by human peripheral blood mononuclear cells - chemically injured keratocyte reaction Mol Vis. 2011;17:2665-2671.

22. Williams RN, Paterson CA. The influence of topical corticosteroid therapy upon polymorphonuclear leukocyte distribution, vascular integrity and ascorbate levels in endotoxin-induced inflammation of the rabbit eye. Exp Eye Res. 1987;44(2):191-198.

23. Dana MR, Qian Y, Hamrah P. Twenty-five-year panorama of corneal immunology: emerging concepts in the immunopathogenesis of microbial keratitis, peripheral ulcerative keratitis, and corneal transplant rejection. Cornea. 2000;19(5):625-643.

24. O'Callaghan RJ. Role of exoproteins in bacterial keratitis: the Fourth Annual Thygeson Lecture, presented at the Ocular Microbiology and Immunology Group Meeting, November 7, 1998. Cornea. 1999; 18(5):532-537.

25. Fini ME. Keratocyte and fibroblast phenotypes in the repairing cornea Prog Retin Eye Res. 1999;18(4):529-551.

26. Lim M, Goldstein MH, Tuli S, et al. Growth factor, cytokine and protease interactions during corneal wound healing. Ocul Surf. 2003; 1(2):53-65.

27. Chung JH, Kang YG, Kim HJ. Effect of $0.1 \%$ dexamethasone on epithelial healing in experimental corneal alkali wounds: morphological changes during the repair process. Graefes Arch Clin Exp Ophthalmol. 1998;236(7):537-545.

28. Tomas-Barberan S, Fagerholm P. Influence of topical treatment on epithelial wound healing and pain in the early postoperative period following photorefractive keratectomy. Acta Ophthalmol Scand. 1999; 77(2):135-138.

29. Gritz DC, Lee TY, Kwitko S, et al. Topical anti-inflammatory agents in an animal model of microbial keratitis. Arch Ophthalmol. 1990;108(7): 1001-1005.

30. Gritz DC, Kwitko S, Trousdale MD, et al. Recurrence of microbial keratitis concomitant with antiinflammatory treatment in an animal model. Cornea. 1992;11(5):404-408.

31. Carmichael TR, Gelfand Y, Welsh NH. Topical steroids in the treatment of central and paracentral corneal ulcers. Br J Ophthalmol. 1990; 74(9):528-531.

32. Srinivasan M, Lalitha $\mathrm{P}$, Mahalakshmi R, et al. Corticosteroids for bacterial corneal ulcers. Br J Ophthalmol. 2009;93(2):198-202.

33. Blair J, Hodge W, Al-Ghamdi S, et al. Comparison of antibiotic-only and antibiotic-steroid combination treatment in corneal ulcer patients: double-blinded randomized clinical trial. Can J Ophthalmol. 2011; 46(1):40-45.

34. Srinivasan M, Mascarenhas J, Rajaraman R, et al. Corticosteroids for bacterial keratitis: the Steroids for Corneal Ulcers Trial (SCUT). Arch Ophthalmol. 2012;130(2):143-150.

35. Srinivasan M, Mascarenhas J, Rajaraman R, et al. The steroids for corneal ulcers trial: study design and baseline characteristics. Arch Ophthalmol. 2012;130(2):151-157.
36. Herretes S, Wang X, Reyes JM. Topical corticosteroids as adjunctive therapy for bacterial keratitis. Cochrane Database Syst Rev. 2014;10: CD005430.

37. Lalitha P, Srinivasan M, Manikandan P, et al. Relationship of in vitro susceptibility to moxifloxacin and in vivo clinical outcome in bacterial keratitis. Clin Infect Dis. 2012;54(10):1381-1387.

38. Lalitha P, Srinivasan M, Rajaraman R, et al. Nocardia keratitis: clinical course and effect of corticosteroids. Am J Ophthalmol. 2012; 154(6):934-939.e1.

39. McClintic SM, Prajna NV, Srinivasan M, et al. Visual outcomes in treated bacterial keratitis: four years of prospective follow-up. Invest Ophthalmol Vis Sci. 2014;55(5):2935-2940.

40. Oldenburg CE, Lalitha P, Srinivasan M, et al. Moxifloxacin susceptibility mediates the relationship between causative organism and clinical outcome in bacterial keratitis. Invest Ophthalmol Vis Sci. 2013; 54(2):1522-1526.

41. Ray KJ, Prajna L, Srinivasan M, et al. Fluoroquinolone treatment and susceptibility of isolates from bacterial keratitis. JAMA Ophthalmol. 2013;131(3):310-313

42. Ray KJ, Srinivasan M, Mascarenhas J, et al. Early addition of topical corticosteroids in the treatment of bacterial keratitis. JAMA Ophthalmol. 2014;132(6):737-741

43. See CW, Srinivasan M, Saravanan S, et al. Prior elicitation and Bayesian analysis of the Steroids for Corneal Ulcers Trial. Ophthalmic Epidemiol. 2012;19(6):407-413.

44. Srinivasan M, Mascarenhas J, Rajaraman R, et al. The steroids for corneal ulcers trial (SCUT): secondary 12-month clinical outcomes of a randomized controlled trial. Am J Ophthalmol. 2014;157(2): 327-333.e3.

45. Srinivasan M, Mascarenhas J, Rajaraman R, et al. Visual recovery in treated bacterial keratitis. Ophthalmology. 2014;121(6):1310-1311.

46. Sy A, Srinivasan M, Mascarenhas J, et al. Pseudomonas aeruginosa keratitis: outcomes and response to corticosteroid treatment. Invest Ophthalmol Vis Sci. 2012;53(1):267-272.

47. Borkar DS, Fleiszig SM, Leong C, et al. Association between cytotoxic and invasive Pseudomonas aeruginosa and clinical outcomes in bacterial keratitis. JAMA Ophthalmol. 2013;131(2):147-153.

48. Akova YA, Onat M, Koc F, et al. Microbial keratitis following penetrating keratoplasty. Ophthalmic Surg Lasers. 1999;30(6):449-455.

49. Bates AK, Kirkness CM, Ficker LA, et al. Microbial keratitis after penetrating keratoplasty. Eye (Lond). 1990;4(pt 1):74-78.

50. Christo CG, van Rooij J, Geerards AJ, et al. Suture-related complications following keratoplasty: a 5-year retrospective study. Cornea. 2001; 20(8):816-819.

51. Tavakkoli H, Sugar J. Microbial keratitis following penetrating keratoplasty. Ophthalmic Surg. 1994;25(6):356-360.

52. Tuberville AW, Wood TO. Corneal ulcers in corneal transplants. Curr Eye Res. 1981;1(8):479-485.

53. Wagoner MD, Al-Swailem SA, Sutphin JE, et al. Bacterial keratitis after penetrating keratoplasty: incidence, microbiological profile, graft survival, and visual outcome. Ophthalmology. 2007;114(6):1073-1079.

54. Wright TM, Afshari NA. Microbial keratitis following corneal transplantation. Am J Ophthalmol. 2006;142(6):1061-1062.

55. Al-Hazzaa SA, Tabbara KF. Bacterial keratitis after penetrating keratoplasty. Ophthalmology. 1988;95(11):1504-1508.

56. Huang SC, Wu SC, Wu WC, et al. Microbial keratitis - a late complication of penetrating keratoplasty. Trans R Soc Trop Med Hyg. 2000; 94(3):315-317.

57. Tseng SH, Ling KC. Late microbial keratitis after corneal transplantation. Cornea. 1995;14(6):591-594.

58. Vajpayee RB, Boral SK, Dada T, et al. Risk factors for graft infection in India: a case-control study. Br J Ophthalmol. 2002;86(3):261-265.

59. Vajpayee RB, Sharma N, Sinha R, et al. Infectious keratitis following keratoplasty. Surv Ophthalmol. 2007;52(1):1-12. 


\section{Publish your work in this journal}

Clinical Ophthalmology is an international, peer-reviewed journal covering all subspecialties within ophthalmology. Key topics include: Optometry; Visual science; Pharmacology and drug therapy in eye diseases; Basic Sciences; Primary and Secondary eye care; Patient Safety and Quality of Care Improvements. This journal is indexed on

Submit your manuscript here: http://www.dovepress.com/clinical-ophthalmology-journal
PubMed Central and CAS, and is the official journal of The Society of Clinical Ophthalmology (SCO). The manuscript management system is completely online and includes a very quick and fair peer-review system, which is all easy to use. Visit http://www.dovepress.com/ testimonials.php to read real quotes from published authors. 